Published in final edited form as:

Ann Surg Oncol. 2018 October ; 25(10): 2884-2889. doi:10.1245/s10434-018-6598-z.

\title{
Lymph Node Status in Breast Cancer Does Not Predict Tumor Biology
}

\author{
Danielle M. Bello, MD¹, Christy Russell, MD², Debbie McCullough, MS², Marni Tierno, PhD, \\ $\mathbf{R N}^{2}$, and Monica Morrow, $\mathbf{M D}^{1}$ \\ ${ }^{1}$ Breast Service, Department of Surgery, Memorial Sloan Kettering Cancer Center, New York, NY \\ ${ }^{2}$ Genomic Health, Redwood City, CA
}

\begin{abstract}
Background/Objective.-The 21-gene Oncotype DX® Breast Recurrence Score ${ }^{\circledR}(\mathrm{RS})$ assay has been prospectively validated as prognostic and predictive in node-negative estrogen receptorpositive (ER+)/HER2-breast cancer patients. Less is known about its prognostic role in nodepositive breast cancer. We compared RS results among patients with lymph node-negative (N0), micrometastatic $(\mathrm{N} 1 \mathrm{mi})$, and macrometastatic $(\mathrm{N}+)$ breast cancer to determine if nodal metastases are associated with more aggressive biology as determined by RS.
\end{abstract}

Methods.-610,350 tumor specimens examined by the Genomic Health laboratory from 2/2004$8 / 2017$ were studied. Histology was classified centrally; lymph node status was determined locally. RS distribution (Low<18; Intermediate 18-30; High 231 ) was compared by nodal status.

Results.-80\% ( $\mathrm{n}=486,013)$ of patients were N0, 4\% ( $\mathrm{n}=24,325)$ were N1mi, 9\% ( $\mathrm{n}=56,100)$ were $\mathrm{N}+; 7 \%(\mathrm{n}=43,912)$ had unknown nodal status. Mean RS result was 18, 16.7, 17.3, and 18.9 in the $\mathrm{N} 0, \mathrm{~N} 1 \mathrm{mi}, \mathrm{N}+$, and unknown groups, respectively. RS $\geq 31$ were seen in $10 \%$ of $\mathrm{N} 0,7 \%$ of $\mathrm{N} 1 \mathrm{mi}$, and $8.0 \%$ of $\mathrm{N}+$ patients. Likelihood of a RS $\geq 31$ in $\mathrm{N} 1 \mathrm{mi}$ and $\mathrm{N}+$ patients varied with tumor histology, with only $2 \%$ of patients with classic infiltrating lobular cancer having a RS $\geq 31$ versus 7-9\% of those with ductal carcinoma.

Conclusions.- RS distribution among N0, N1mic, and N+ patients is similar, suggesting a spectrum of biology and potential chemotherapy benefit exists among node-negative and nodepositive ER+/HER2- breast cancer patients. If RxPONDER does not show a chemotherapy benefit in $\mathrm{N}+$ patients with a low RS result, our findings indicate that substantial numbers of patients could be spared the burden of chemotherapy.

\section{Keywords}

Oncotype DX Breast Recurrence Score; breast cancer; chemotherapy; micrometastatic breast cancer; macrometastatic breast cancer

Corresponding author: Monica Morrow MD, Breast Service, Department of Surgery, Memorial Sloan Kettering Cancer Center, 300 East 66th Street, New York, NY 10065,(T) 646888 5350, (F) 646888 5365, morrowm@ @mskcc.org. 


\section{INTRODUCTION}

Lymph node status in breast cancer has historically been considered the most important prognostic factor determining disease-specific and overall survival. Demonstration in the Early Breast Cancer Trialists' Collaborative Group overview analysis that the combination of chemotherapy and hormonal therapy halved the risk of breast cancer mortality in women with estrogen receptor positive (ER+) cancers led this treatment to be considered standard in patients with node-positive breast cancer. ${ }^{1-3}$ However, it is recognized that not all ER+ patients derive the same benefit from adjuvant chemotherapy. ${ }^{4,5}$

More recently, molecular assays such as the Oncotype DX 21-gene Breast CancerRecurrence Score ${ }^{\circledR}$ (RS) (Genomic Health, Redwood City, CA) have been shown to more reliably predict prognosis than standard histopathologic features in hormone receptor positive (HR+)/HER2 negative (HER2-) breast cancer patients with and without axillary nodal metastases treated with endocrine therapy. ${ }^{6-11}$ The excellent prognosis for nodenegative patients with low RS results after treatment with endocrine therapy alone has been demonstrated in a prospective study and in population-based registries. ${ }^{12,13}$ A retrospective analysis of the National Surgical Adjuvant Breast and Bowel Project (NSABP) B20 trial suggests that the RS result also predicts the benefit of chemotherapy in node-negative women, and this hypothesis is being tested in the TAILORx study. ${ }^{6}$ Both National Comprehensive Cancer Network (NCCN) and American Society of Clinical Oncology (ASCO) guidelines recommend the use of the RS assay in patients with ER+/HER2-, lymph node negative or micrometastatic tumors $>5 \mathrm{~mm}$ in size. The role of the RS result in patients with nodal metastases has been examined using archived tumors from clinical trials, and results are similar to those seen in node-negative patients. ${ }^{6,7}$ However, patients with nodal metastases have been studied in much more limited numbers, and it is unclear if the same spectrum of low- and high-risk RS results exists among node-positive patients.

The purpose of this study was to compare RS results among patients with lymph node negative (N0), micrometastatic (N1mi), and macrometastatic $(\mathrm{N}+)$ breast cancer to determine if the distribution of RS results varies with nodal status.

\section{METHODS}

A total of 619,866 invasive breast cancer specimens examined in the Genomic Health clinical laboratory in the United States from 02/2004-08/2017 were identified. After exclusion of 9516 samples due to missing histologic subtype $(n=9,284)$ or recording of more than one histologic subtype $(\mathrm{n}=232), 610,350$ tumor specimens comprised the study population. Histologic subtype was classified centrally using World Health Organization criteria by board certified surgical pathologists after review of a single hematoxylin and eosin slide. ${ }^{14}$ Lymph node status was determined by local review, and patients were classified as having lymph node negative (N0), micrometastatic (N1 mi), or macrometastatic $(\mathrm{N}+)$ nodal disease. ${ }^{15}$ Invasive breast cancer tumor specimens classified as ductal, lobular (classic or other variants), mixed ductal/lobular, tubular, papillary, mucinous, and cribriform were included in this study. 
The Oncotype DX 21-gene Breast Recurrence Score ${ }^{\circledR}$ algorithm is based upon quantitative expression of 16 cancer-related genes and 5 reference genes, which has been previously described. ${ }^{16}$ The expression of these genes is measured in triplicate using reverse transcription polymerase chain reaction (RT-PCR) from formalin fixed, paraffin-embedded tumor tissue. RS results range from 0-100, where a higher score indicates an increased risk of recurrence.

IRB approval was waived due to the de-identified nature of this outside dataset.

\section{Statistical Analysis}

Descriptive statistics were calculated for the RS result based on originally reported cutoffs (Low <18; Intermediate 18-30; High 31 ) as well as the cutoff points used for the RxPONDER (Low 25 and High $>25$ ) clinical trial. ${ }^{10}$ RS distribution was analyzed by histologic subtype and nodal status. Continuous variables are reported as the mean, median, and interquartile range (IQR). Because of the large study sample size, all analyses are descriptive since even small differences between groups were expected to be statistically significant, but potentially not clinically meaningful. All analyses were performed on deidentified data.

\section{RESULTS}

A total of 610,350 breast cancer specimens were included in the study. The majority of patients were node negative $(80 \%, \mathrm{n}=486,013) ; 4 \%(\mathrm{n}=24,325)$ had micrometastatic disease $(\mathrm{N} 1 \mathrm{mi}), 9 \%(\mathrm{n}=56,100)$ had macrometastases $(\mathrm{N}+)$, and $7 \%(\mathrm{n}=43,912)$ had unknown nodal status (not reported to Genomic Health or nodes not sampled). The median patient age was 60 years (IQR 51-67 years) in N0 and N1mi patients, 62 years in N+ patients (IQR 52-70), and 61 years in the unknown nodal status patients (IQR 52-68). Patients older than 50 years of age comprised $76 \%(n=371,283), 77 \% \%(n=18,665), 81 \%(n=45,553)$, and $78 \%$ $(n=34,393)$ of patients in the N0, N1mi, N+, and unknown nodal groups, respectively.

The mean RS result was similar across nodal subgroups; 18.0 in the N0 group, 16.7 in the N1mi group, 17.3 in the $\mathrm{N}+$ group, and 18.9 in the unknown group. The majority of patients in all nodal subgroups had RS $<18$ (Table 1). RS $<18$ was seen in 59\% $(\mathrm{n}=286,504 / 486,013)$ of N0 patients, $64 \%(n=15,463 / 24,325)$ of N1mi patients, and $62 \%(n=34,603 / 56,100)$ of N+ patients. Similarly, there was little variation in the rate of RS $\geq 31$ based upon nodal status (Fig. 1).

When results were examined using the cutoffs for the RxPONDER trial, the majority of patients remained in the low risk (RS $\left.\_5\right)$ group. RS $\_5$ was recorded in $83 \%(n=403,944)$ of N0 patients, $87 \%(\mathrm{n}=21,052)$ of N1mi patients, and $85 \%(\mathrm{n}=47,819)$ of $\mathrm{N}+$ patients, while the rate of RS > 25 was $17 \%, 13 \%$, and $15 \%$ in the N0, N1mi and N+ patients, respectively (Fig. 1).

Rates of nodal macrometastases among histologic subtypes ranged from $4 \%$ to $12 \%$, with macrometastases most frequent in carcinoma of mixed ductal and lobular histology (12\%), lobular carcinoma, of classic type (11\%), and infiltrating ductal carcinoma, not otherwise 
specified (NOS) (9\%). As expected, macrometastases were infrequent among the tumors of special histologic subtype, being present in $3 \%$ of tubular cancers, and $4 \%$ of mucinous and papillary cancers. The distribution of mean RS results according to nodal status and histologic subtype is shown in Table 2. Even after controlling for histology, mean RS results did not vary substantially by nodal status. For example, in the infiltrating ductal NOS group, mean RS results for node-negative, micrometastatic, macrometastatic, and unknown nodal status patients were $18.5,17,17.6$, and 19.4, respectively. In the mucinous carcinoma patients, RS results for node-negative, micrometastatic, macrometastatic, and unknown nodal status were $14.9,14.8,15$, and 15 , respectively.

Greater variation in the proportion of patients having high RS results was seen based upon histology rather than upon nodal status. RS $\geq 31$ was present in $11 \%$ of patients with infiltrating ductal carcinomas NOS, $4 \%$ of those with mucinous carcinomas, and $0.5 \%$ of those with tubular carcinoma. Within the ductal group, the proportion of patients with RS 231 was $11 \%$ for $\mathrm{N} 0$ and $9 \%$ for $\mathrm{N}+$ patients. For those with mucinous carcinoma, $4 \%$ of patients with either N0 or N+ had high RS results, while for those with tubular carcinoma, RS $\geq 31$ were seen in $0.4 \%$ of N0 patients and $0.8 \%$ of $\mathrm{N}+$ patients (Table 3). Using the RxPONDER cutoff of an RS $>25$ to define the high-risk group, similar results were seen with greater variation based on histology than nodal status (data not shown). For either the standard cutpoints or the RxPONDER cutpoints, histologies associated with a favorable prognosis, such as tubular, mucinous, cribriform, and papillary, infrequently had high RS results, regardless of nodal status, and the frequency of high RS results also did not vary based on nodal status among the more common ductal and lobular cancers.

\section{DISCUSSION}

Incorporation of the RS result into clinical decision making has led to dramatic reductions in chemotherapy use among patients with node-negative breast cancer. ${ }^{17-20}$ In this study evaluating RS results among N0, N1mic, and N+ patients, RS results were similar among patients with and without nodal metastases, suggesting that just as the RS result identifies a spectrum of biology and predicts benefit of chemotherapy among ER+/HER2, N0 patients, the same biologic spectrum exists within patients with nodal metastases.

Multiple studies have demonstrated the prognostic value of the RS assay in ER+/HER2patients with 1-3 nodal metastases. Dowsett et al examined RS results in both node-positive and node-negative postmenopausal women using samples from the tamoxifen and anastrozole treatment arms of the Arimidex, Tamoxifen, Alone or in Combination (ATAC) Trial and showed that the RS result was significantly associated with the risk of distant recurrence in women with and without nodal metastases. The 9-year distant recurrence rates after treatment with endocrine therapy alone in the low (RS <18), intermediate (RS 18-30), and high (RS 231 ) RS groups were $4 \%, 12 \%$, and $25 \%$, respectively, in N0 patients, and $17 \%, 28 \%$, and $49 \%$, respectively, in patients with any number of positive nodes. In each of the RS groups, the risk of distant recurrence was higher in the node-positive than the nodenegative patients, emphasizing that nodal status remains an independent prognostic factor. However, there were only 306 node-positive patients included in this study. ${ }^{21}$ 
A previous analysis of the Genomic Health database by Swain et al examining over 394,000 patients, including over 30,000 N+ patients, showed that the distribution of the RS result in patients with 1-3 nodal metastases was similar to that of $\mathrm{N} 0$ patients, with $61 \%$ having a low RS vs $58 \%$, and $7 \%$ vs $8.5 \%$ with a high RS, respectively. ${ }^{22}$ These data are comparable to our results using a larger cohort of 610,350 patients, including over 43,000 patients with $\mathrm{N}+$ disease. In our study, $62 \%$ of $\mathrm{N}+$ patients had a low RS compared to $59 \%$ of $\mathrm{N} 0$ patients, and $8 \%$ of $\mathrm{N}+$ patients vs $10 \%$ of N0 patients had a high RS. Swain et al also demonstrated that $\mathrm{N}+$ patients $40-50$ years of age and those $\geq 70$ years of age had a similar proportion of high RS results, $7 \%$ and $9 \%$, respectively, suggesting that age was not as informative of the underlying tumor biology as the RS result.

Roberts et al used the Surveillance, Epidemiology and End Results (SEER) database to examine the impact of the number of nodes containing metastases on distribution of RS results. ${ }^{12,23}$ Among the 6768 patients with nodal metastases, clinical and pathologic features were comparable to those in the SEER N0 cohort; most tumors were 1-2cm in size and grade 2. Micrometastases were present in $42 \%$. In remaining patients, $39 \%$ had 1 positive node, $11 \%$ had 2 positive nodes, and $4 \%$ had 3 positive nodes. The majority of patients with micrometastases $(58 \%)$ or involvement of 1-3 nodes with metastases had RS $<18$. For those with 1 involved node, $59 \%$ had a RS < 18 compared to $51 \%$ with 3 involved nodes. In those with involvement of $\geq 4$ nodes ( $\mathrm{n}=285)$, only $45 \%$ had a RS $<18$. A similar pattern was seen for RS $\geq 31$, which increased from $7 \%$ in patients with 1 nodal metastases to $11 \%$ in those with 3 nodal metastases and $14 \%$ in those with $\geq 4$ metastases. These data parallel our results in a larger population, with $64 \%$ of patients with micrometastases and $62 \%$ of the group with macrometastases having RS $<18$.

The studies discussed above support our finding that the distribution of the RS results between patients with $\mathrm{N} 0, \mathrm{~N} 1 \mathrm{mic}$, and $\mathrm{N}+$ disease is similar, with the majority having RS $<18 .{ }^{12,22,23}$ One possible explanation for this is the selection of node-positive patients with favorable histologic features to undergo the RS test. To address this issue, we examined RS results by histology. RS $\geq 31$ were similar among $\mathrm{N} 0$ and $\mathrm{N}+$ patients after stratification by subtype, even among the 504,362 patients with infiltrating ductal carcinoma NOS, indicating that this finding was not solely due to enrichment of the $\mathrm{N}+$ group with tumors of favorable histologies. Additionally, the distribution of nodal metastases varied by histologic subtype as would be anticipated, being 3-4 times more common in the ductal, lobular, and mixed ductal and lobular carcinomas than in the tubular, mucinous, and papillary carcinomas, further suggesting that our findings cannot solely be attributed to selection bias.

Both SEER studies examining survival outcomes in $\mathrm{N} 0$ and $\mathrm{N}+$ patients have demonstrated that RS was significantly associated with 5-year breast cancer-specific mortality (BCSM) in $\mathrm{N} 1 \mathrm{mi}$ and $\mathrm{N}+$ patients. Notably, 5-year BCSM was $1.3 \%$ or lower for patients with RS results $<18$, regardless of nodal status. The unadjusted 5-year BCSM rates for the RS $<18$, RS 18-30, and RS $\geq 31$ in node-positive patients were $1.0 \%, 2.3 \%$, and $14.3 \%$, respectively. 12 Of note, the 5-year BCSM for the 21,000+ N0 patients with a RS $<18$ was $0.4 \%$, emphasizing that while our study does not demonstrate a difference in the distribution of RS results based on nodal status, nodal status remains an important prognostic factor in breast cancer. ${ }^{12}$ The West German Study Group Plan B study similarly showed a 5-year disease- 
free survival of $94 \%$ in N0 patients and those with involvement of 1-3 nodes and an RS result of $\unlhd 1$ treated with hormone therapy alone. ${ }^{24}$

In patients with node-negative breast cancer, the major clinical utility of the RS result is the identification of patients with a good prognosis who do not benefit from the addition of chemotherapy to endocrine therapy. A retrospective analysis of RS results in 367 of the 927 $\mathrm{N}+$ postmenopausal patients enrolled in the SWOG S8814 study which demonstrated improved survival with the addition of cyclophosphamide, doxorubicin, and fluorouracil (CAF) to tamoxifen suggests a similar predictive role in $\mathrm{N}+$ women. In this study, N+ patients with a RS $<18$ derived no benefit from the addition of chemotherapy to tamoxifen, whereas patients with a RS $\geq 31$ had a $25 \%$ improvement in breast cancer-specific survival when treated with chemotherapy. ${ }^{7}$

Although the trans-ATAC ${ }^{21}, \mathrm{PlanB}^{25}$, and SWOG S8814 ${ }^{7}$ analyses indicate that the RS result is prognostic in $\mathrm{N}+$ patients, and the SWOG S8814 trial ${ }^{7}$ suggests that it is predictive of the benefit of chemotherapy, this question is being definitively addressed in the RxPONDER trial in which women with ER+/HER2- breast cancer with 1-3 positive nodes and a RS result $\_5$ are randomized to receive adjuvant endocrine therapy with or without chemotherapy. If the RxPONDER trial demonstrates no benefit for chemotherapy in the RS $\measuredangle 25$ group, the findings of our study demonstrating that a large proportion of women with nodal metastases have low RS results suggests that a substantial number of N+ women can be treated with endocrine therapy alone.

Strengths of our study include the very large sample size of more than 55,000 N+ patients and 24,000 N1mi patients, and the ability to examine RS results by histologic subtype. One potential weakness is that our findings may reflect selection of more favorable $\mathrm{N}+$ patients for the RS assay. However, the large sample size and consistency of results across tumor subtypes support the finding that there may be significant numbers of women with $\mathrm{N}+$ disease at low risk for recurrence after treatment with endocrine therapy alone. Other limitations of our analysis include the absence of treatment information, other clinicopathologic characteristics (e.g., race, size, and grade), and clinical outcomes.

\section{Conclusions}

Our study indicates that RS results among N0, N1mic, and N+ patients are similar, suggesting that just as the RS identifies a spectrum of biology and predicts benefit of chemotherapy among ER+/HER2-, N0 patients, the same biologic spectrum exists within patients with nodal metastases. If the RxPONDER trial demonstrates a predictive benefit for the RS result in $\mathrm{N}+$ women, our findings suggest that substantial numbers of patients could be spared the burden of chemotherapy.

\section{Acknowledgments}

\section{AUTHORS' DISCLOSURE OF POTENTIAL CONFLICTS OF INTEREST}

The preparation of this manuscript was funded in part by NIH/NCI Cancer Center Support Grant No. P30 CA 0087348 to Memorial Sloan Kettering Cancer Center, and this study was presented in podium format at the $19^{\text {th }}$ Annual Meeting of the American Society of Breast Surgeons, May 2-6, 2018, Orlando, FL. Dr. Monica Morrow is a consultant for Genomic Health. 


\section{REFERENCES}

1. Coates AS, Winer EP, Goldhirsch A, Gelber RD, Gnant M, Piccart-Gebhart M, Thurlimann B, et al. Tailoring therapies--improving the management of early breast cancer: St Gallen International Expert Consensus on the Primary Therapy of Early Breast Cancer 2015. Ann Oncol. 2015;26(8): 1533-46. [PubMed: 25939896]

2. Denduluri N, Somerfield MR, Eisen A, Holloway JN, Hurria A, King TA, Lyman GH, et al. Selection of Optimal Adjuvant Chemotherapy Regimens for Human Epidermal Growth Factor Receptor 2 (HER2) -Negative and Adjuvant Targeted Therapy for HER2-Positive Breast Cancers: An American Society of Clinical Oncology Guideline Adaptation of the Cancer Care Ontario Clinical Practice Guideline. J Clin Oncol. 2016;34(20):2416-27. [PubMed: 27091714]

3. Eisen A, Fletcher GG, Gandhi S, Mates M, Freedman OC, Dent SF, Trudeau ME, et al. Optimal systemic therapy for early breast cancer in women: a clinical practice guideline. Curr Oncol. 2015;22(Suppl 1):S67-81. [PubMed: 25848340]

4. Early Breast Cancer Trialists' Collaborative G. Effects of chemotherapy and hormonal therapy for early breast cancer on recurrence and 15-year survival: an overview of the randomised trials. Lancet. 2005;365(9472):1687-717. [PubMed: 15894097]

5. Early Breast Cancer Trialists' Collaborative G, R Peto, C Davies, J Godwin, R Gray, HC Pan, M Clarke, et al. Comparisons between different polychemotherapy regimens for early breast cancer: meta-analyses of long-term outcome among 100,000 women in 123 randomised trials. Lancet. 2012;379(9814):432-44. [PubMed: 22152853]

6. Paik S, Tang G, Shak S, Kim C, Baker J, Kim W, Cronin M, et al. Gene expression and benefit of chemotherapy in women with node-negative, estrogen receptor-positive breast cancer. J Clin Oncol. 2006;24(23):3726-34. [PubMed: 16720680]

7. Albain KS, Barlow WE, Shak S, Hortobagyi GN, Livingston RB, Yeh IT, Ravdin P, et al. Prognostic and predictive value of the 21-gene recurrence score assay in postmenopausal women with nodepositive, oestrogen-receptor-positive breast cancer on chemotherapy: a retrospective analysis of a randomised trial. Lancet Oncol. 2010;11(1):55-65. [PubMed: 20005174]

8. Harris L, Fritsche H, Mennel R, Norton L, Ravdin P, Taube S, Somerfield MR, et al. American Society of Clinical Oncology 2007 update of recommendations for the use of tumor markers in breast cancer. J Clin Oncol. 2007;25(33):5287-312. [PubMed: 17954709]

9. Hassett MJ, Silver SM, Hughes ME, Blayney DW, Edge SB, Herman JG, Hudis CA, et al. Adoption of gene expression profile testing and association with use of chemotherapy among women with breast cancer. J Clin Oncol. 2012;30(18):2218-26. [PubMed: 22585699]

10. Ramsey SD, Barlow WE, Gonzalez-Angulo AM, Tunis S, Baker L, Crowley J, Deverka P, et al. Integrating comparative effectiveness design elements and endpoints into a phase III, randomized clinical trial (SWOG S1007) evaluating oncotypeDX-guided management for women with breast cancer involving lymph nodes. Contemp Clin Trials. 2013;34(1):1-9. [PubMed: 23000081]

11. Dinan MA, Mi X, Reed SD, Lyman GH, Curtis LH. Association Between Use of the 21-Gene Recurrence Score Assay and Receipt of Chemotherapy Among Medicare Beneficiaries With Early-Stage Breast Cancer, 2005-2009. JAMA Oncol. 2015;1(8):1098-109. [PubMed: 26313372]

12. Petkov VI, Miller DP, Howlader N, Gliner N, Howe W, Schussler N, Cronin K, et al. Breastcancer-specific mortality in patients treated based on the 21-gene assay: a SEER population-based study. NPJ Breast Cancer. 2016;2:16017. [PubMed: 28721379]

13. Sparano JA, Gray RJ, Makower DF, Pritchard KI, Albain KS, Hayes DF, Geyer CE, Jr., et al. Prospective Validation of a 21-Gene Expression Assay in Breast Cancer. N Engl J Med. 2015;373(21):2005-14. [PubMed: 26412349]

14. Lakhani SREI, Schnitt SJ, Tan PH, van de Vijver MJ, ed. WHO Classification of Tumours of the Breast. 4 ed: International Agency for Research on Cancer; 2012.

15. Edge SB, Byrd DR, Compton CC, Fritz AG, Greene FL. American Joint Committee on Cancer (AJCC) Cancer Staging Manual, 7th Edition 2010 Springer New York.

16. Paik S, Shak S, Tang G, Kim C, Baker J, Cronin M, Baehner FL, et al. A multigene assay to predict recurrence of tamoxifen-treated, node-negative breast cancer. N Engl J Med. 2004;351(27): 2817-26. [PubMed: 15591335] 
17. Gradishar WJ, Anderson BO, Balassanian R, Blair SL, Burstein HJ, Cyr A, Elias AD, et al. Invasive Breast Cancer Version 1.2016, NCCN Clinical Practice Guidelines in Oncology. J Natl Compr Canc Netw. 2016;14(3):324-54. [PubMed: 26957618]

18. Harris LN, Ismaila N, McShane LM, Andre F, Collyar DE, Gonzalez-Angulo AM, Hammond EH, et al. Use of Biomarkers to Guide Decisions on Adjuvant Systemic Therapy for Women With Early-Stage Invasive Breast Cancer: American Society of Clinical Oncology Clinical Practice Guideline. J Clin Oncol. 2016;34(10):1134-50. [PubMed: 26858339]

19. Kurian AW, Bondarenko I, Jagsi R, Friese CR, McLeod MC, Hawley ST, Hamilton AS, et al. Recent Trends in Chemotherapy Use and Oncologists' Treatment Recommendations for EarlyStage Breast Cancer. J Natl Cancer Inst. 2017.

20. Jasem J, Amini A, Rabinovitch R, Borges VF, Elias A, Fisher CM, Kabos P. 21-Gene Recurrence Score Assay As a Predictor of Adjuvant Chemotherapy Administration for Early-Stage Breast Cancer: An Analysis of Use, Therapeutic Implications, and Disparity Profile. J Clin Oncol. 2016;34(17):1995-2002. [PubMed: 27001563]

21. Dowsett M, Cuzick J, Wale C, Forbes J, Mallon EA, Salter J, Quinn E, et al. Prediction of risk of distant recurrence using the 21-gene recurrence score in node-negative and node-positive postmenopausal patients with breast cancer treated with anastrozole or tamoxifen: a TransATAC study. J Clin Oncol. 2010;28(11):1829-34. [PubMed: 20212256]

22. Swain SM, Nunes R, Yoshizawa C, Rothney M, Sing AP. Quantitative Gene Expression by Recurrence Score in ER-Positive Breast Cancer, by Age. Adv Ther. 2015;32(12):1222-36. [PubMed: 26610382]

23. Roberts MC, Miller DP, Shak S, Petkov VI. Breast cancer-specific survival in patients with lymph node-positive hormone receptor-positive invasive breast cancer and Oncotype DX Recurrence Score results in the SEER database. Breast Cancer Res Treat. 2017;163(2):303-10. [PubMed: 28243896]

24. Nitz U, Gluz O, Christgen M, Kates RE, Clemens M, Malter W, Nuding B, et al. Reducing chemotherapy use in clinically high-risk, genomically low-risk pN0 and pN1 early breast cancer patients: five-year data from the prospective, randomised phase 3 West German Study Group (WSG) PlanB trial. Breast Cancer Res Treat. 2017;165(3):573-83. [PubMed: 28664507]

25. Gluz O, Nitz UA, Christgen M, Kates RE, Shak S, Clemens M, Kraemer S, et al. West German Study Group Phase III PlanB Trial: First Prospective Outcome Data for the 21-Gene Recurrence Score Assay and Concordance of Prognostic Markers by Central and Local Pathology Assessment. J Clin Oncol. 2016;34(20):2341-9. [PubMed: 26926676] 


\section{Synopsis:}

RS results were compared among patients with $\mathrm{N} 0, \mathrm{~N} 1 \mathrm{mi}$, and $\mathrm{N}+$ breast cancer to determine nodal metastases association with more aggressive biology. We found the istribution of RS results among breast cancer patients with different nodal disease burdens is similar. 


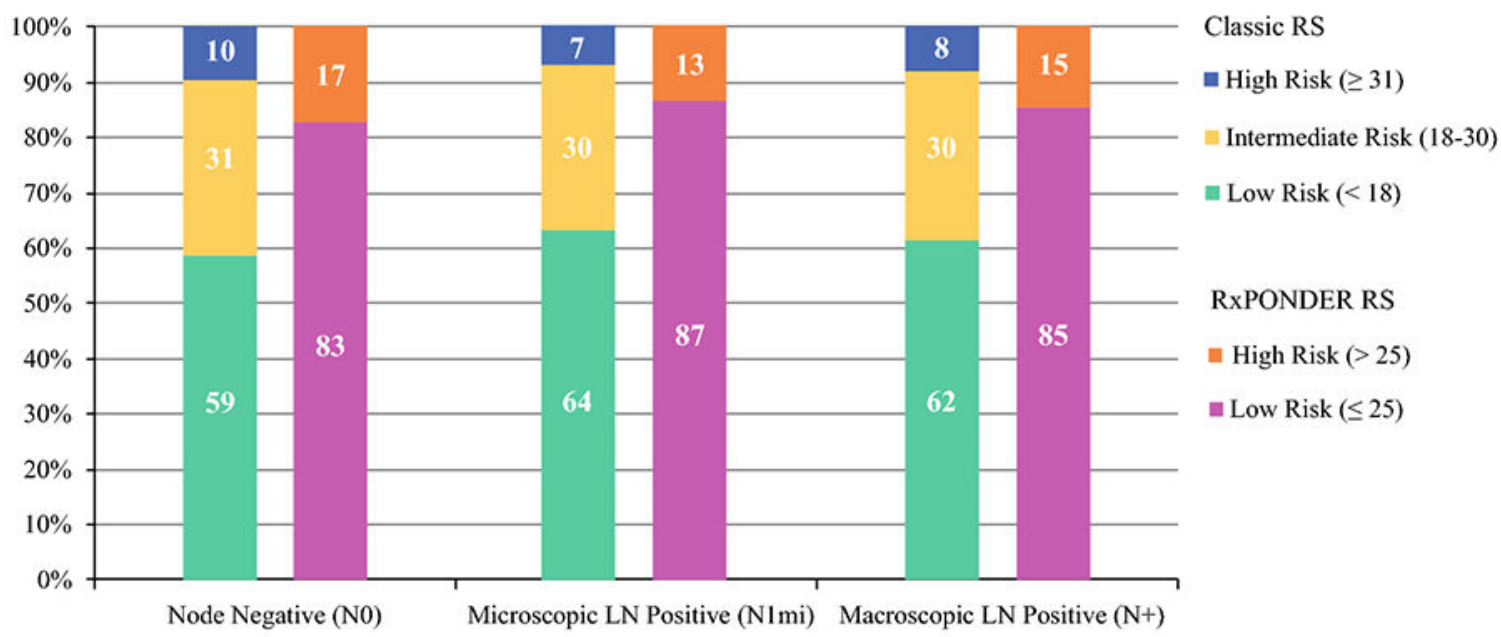

Fig. 1.

Distribution of recurrence scores by nodal status using standard and RxPONDER cutoffs. 
TABLE 1

Recurrence Score results by nodal status

\begin{tabular}{|l|c|c|c|c|}
\hline Nodal Status & \multicolumn{4}{|c|}{ Recurrence Score (RS) Risk Group, N } \\
\hline & Mean RS (SD) & Low (< 18) & Intermediate (18-30) & High (> 31) \\
\hline N0 (n= 486,013) & $18(10.9)$ & $286,50459 \%$ & $152,91331 \%$ & $46,59610 \%$ \\
\hline N1mi $(\mathrm{n}=24,325)$ & $16.7(9.5)$ & $15,46364 \%$ & $7,21230 \%$ & $1,6507 \%$ \\
\hline N+ $(\mathrm{n}=56,100)$ & $17.3(10.1)$ & $34,60362 \%$ & $17,02130 \%$ & $4,4768 \%$ \\
\hline Unknown $(\mathrm{n}=43,912)$ & $18.9(12.0)$ & $25,00457 \%$ & $13,60331 \%$ & $5,30512 \%$ \\
\hline
\end{tabular}

RS, recurrence score; SD, standard deviation; $\mathrm{N} 0$, node negative; $\mathrm{N} 1 \mathrm{mi}$, micrometastatic; $\mathrm{N}+$, macrometastatic 


\section{TABLE 2}

Histologic subtype, nodal status and Recurrence Score

\begin{tabular}{|l|c|c|c|c|c|c|}
\hline Nodal Status & \multicolumn{7}{|c|}{ Mean RS by Histology } \\
\hline & $\begin{array}{c}\text { Ductal, NOS }(\mathbf{n} \\
\mathbf{5 0 4 , 3 6 2})\end{array}$ & $\begin{array}{c}\text { Lobular, } \\
\text { Classic Type } \\
\mathbf{4 9 , 8 1 9})\end{array}$ & $\begin{array}{c}\text { Lobular, Other } \\
\text { Variants }(\mathbf{n}= \\
\mathbf{5 0 6 9})\end{array}$ & $\begin{array}{c}\text { Mucinous } \\
\text { Carcinoma }(\mathbf{n}= \\
\mathbf{1 6 , 1 1 6})\end{array}$ & $\begin{array}{c}\text { Papillary } \\
\text { Carcinoma }(\mathbf{n}= \\
\mathbf{4 1 5 9})\end{array}$ & $\begin{array}{c}\text { Tubular } \\
\text { Carcinoma } \\
\text { (n) }=\end{array}$ \\
\hline N0 & 18.5 & 16.3 & 18.2 & 14.9 & 11.1 & 14.5 \\
\hline N1mi & 17.0 & 15.3 & 18.9 & 14.8 & 10.6 & 14.6 \\
\hline N+ & 17.6 & 15.7 & 17.9 & 15.0 & 12.5 & 15.2 \\
\hline Unknown & 19.4 & 16.9 & 18.1 & 15.0 & 9.8 & 14.8 \\
\hline
\end{tabular}

RS, recurrence score; NOS, not otherwise specified; N0, node negative; N1mi, micrometastatic; N+, macrometastatic 
TABLE 3

Recurrence Score results $\geq 31$ by nodal status and histologic subtype

\begin{tabular}{|l|c|c|c|c|c|c|}
\hline Nodal Status & \multicolumn{5}{|c|}{$\%$ RS $\geq \mathbf{3 1}$ by Histologic Subtype } \\
\hline & Ductal, NOS & Lobular, Classic Type & Lobular, Other Variants & Mucinous Carcinoma & Papillary Carcinoma & Tubular Carcinoma \\
\hline N0 & $11 \%$ & $2 \%$ & $8 \%$ & $4 \%$ & $9 \%$ & $0.4 \%$ \\
\hline N+ & $9 \%$ & $2 \%$ & $8 \%$ & $4 \%$ & $11 \%$ & $0.8 \%$ \\
\hline
\end{tabular}

RS, recurrence score; NOS, not otherwise specified; N0, node negative; N+, macrometastatic 